\title{
Service Occupation
}

National Cancer Institute

\section{Source}

National Cancer Institute. Service Occupation. NCI Thesaurus. Code C85488.

An occupation which provides a service to others rather than creating a product. 